http://jmscr.igmpublication.org/home/ ISSN (e)-2347-176x ISSN (p) 2455-0450

crossref DOI: https://dx.doi.org/10.18535/jmscr/v8i7.46

Journal Of Medical Science And Clinical Research

\title{
Comparison between the Efficacy of Conservative Management and Ultrasound Guided Pigtail Catheter Drainage of Uncomplicated Amoebic Liver Abscess
}

\author{
Authors \\ Dr K Phani Jotsna ${ }^{*}$, Dr Aachi. Srinivas ${ }^{2}$, Dr Vinodh Varada ${ }^{3}$ \\ ${ }^{1}$ Postgraduate, Department of General Surgery, GEMS, Srikakulam \\ ${ }^{2}$ Professor, Department of General Surgery, GEMS \\ ${ }^{3}$ Ssistant Professor, Department of General Surgery, GEMS \\ *Corresponding Author \\ Dr K.Phani Jotsna
}

\begin{abstract}
Liver abscess is the most common condition associated with right upper quadrant pain and fever. It is a common disease of the tropical region. Liver abscess is broadly classified into the amoebic and pyogenic liver abscess. Colonic amoebae are mainly responsible for the development of an abscess. The uncomplicated amoebic liver abscess has been managed conservatively with amoebicidal and antibiotics alone or in combination with ultrasound-guided pigtail catheter or pigtail catheter alone too. According to the review of literature, the smaller the amoebic liver abscess successful was the conservative management, whereas the larger sized abscess or complicated abscess (ruptured, pressure effect)required either open or closed drainage. An objective criterion for the management of uncomplicated liver abscess is established in the present study. Through this study, it is possible $t$ know the mode of treatment to a particular patient with reference to the severity of the disease. 40 patients admitted from June 2018 to January 2020 with uncomplicated amoebic liver abscess were included in the present study.they were divided into two study groups 1) conservatively managed 2)PCD (pigtail catheter drainage). The success rate was measured in terms of clinical improvement, reduction of abscess cavity, need for the redo procedure. In the present study, it has been observed that the resolution of uncomplicated amoebic liver abscess is faster and easier with pigtail catheter drainage than who were managed conservatively. From this study, we can conclude that the pigtail catheter is a better modality of treatment for abscess measuring $>6 \mathrm{~cm}$ and conservative management for those measuring $<6 \mathrm{~cm}$

Keywords: Uncomplicated liver abscess, antibiotic therapy, USG guided drainage -pigtail catheter.
\end{abstract}

\section{Introduction}

Liver abscess is a common condition in India and tropical regions. Liver abscess is broadly classified into pyogenic and amoebic liver abscess based on the infecting organism. Colonic amoebae have a main causative role in the development of a liver abscess. The classic presentation of symptoms is fever, right upper quadrant pain, tender hepatomegaly with or without jaundice. Although the clinical presentation widely varies in different patients. Patients present with features of peritonitis if the abscess ruptures and gets 
complicated. Ultrasound and Computed tomography are the mainstay investigations for diagnosing a liver abscess, added on are the chest $\mathrm{X}$-ray to know the displacement of the right hemidiaphragm due to hepatomegaly. Modern treatment has shifted the treatment of liver abscess towards IV antibiotics, amoebicidals, imagingguided percutaneous drainage catheters. ${ }^{(1,2)}$. However, the review of the literature reveals that the treatment of small amoebic liver abscess (single /multiple)is mainly conservative.

In contrast, large amoebic abscess or complicated abscess is treated with either closed or open drainage methods. There are no clear cut guidelines for the management of medium-sized uncomplicated amoebic liver abscess. The present study is an effort to establish the objective criterion for the management of such abscess. This study helps to find out which mode of treatment is ideal with reference to the severity of disease and thereby reducing morbidity and mortality associated with the disease.

\section{Aim of the Study}

1. To study the therapeutic efficacy of conservative management and ultrasoundguided pigtail drainage of Amoebic liver abscess.

2. To compare the two modalities of treatment of an amoebic liver abscess.

3. To study the safety and outcome of ultrasound-guided drainage of abscess

\section{Source of Data}

The material of study comprised of 40 patients who presented to GEMS \& Hospitals and diagnosed as having amoebic liver abscess from June 2018 to January 2020 The diagnosis was based on the history of, fever and pain abdomen with or without a preceding history of diarrhoea and findings of tender hepatomegaly, leucocytosis amoebic serology and ultrasound evidence of amoebic liver abscess. Patients are randomly allocated into two groups,

GROUP I: In this Group, patients were treated with antiamoebic (Metronidazole 500mg three times a day for 10 days ) and antibiotic drugs (Piperacillin \& Tazobsctum 4.5gm twice a day for 10 days ) - 20 Patients

GROUP II: In this group patients were treated by ultrasound-guided indwelling pigtail catheter drainage, in addition to medical management.-20 Patients

\section{Inclusion Criteria}

Patients with amoebic liver abscess with a size of abscess less than $10 \mathrm{cms}$

\section{Exclusion Criteria}

Patients with complicated abscess (rupture, pressure)

Size of abscess $>10 \mathrm{cms}$

Patients with abnormal INR $>1.5$

\section{Methodology}

The patients in the study group were subjected to:

1. Complete history and physical examination

a) Complete blood picture, Liver function tests, Amoebic serology test, Prothrombin time, INR, Ultrasound abdomen, Chest Xray

b) Aspirated pus for culture and sensitivity

c) Air cavitogram was done in Group II patient Amoebic Serology: Enzyme-linked immunosorbent assay (ELISA) for serum IgG antibodies against Entamoeba histolytica was used. were useful in detecting infection by $\mathrm{E}$. histolytica if organism goes extraintestiInterpretation: Tests sample $>0.4$ OD units were considered positive

Air Cavitogram: Air cavitogram was done in Group II patients at the time of removal of the pigtail catheter when the drainage has decreased, and the ultrasound findings suggest that the abscess contents were minimal.

Patients were assessed for abdominal pain, fever, tender hepatomegaly, resolution of the abscess size ultrasonographically or air cavitogram, days of hospital stay, complications. At three to five days, patients were again reassessed, and if they have not responded to the first mode of treatment, 


\section{JMSCR Vol||08||Issue ||07||Page 267-273||July}

the patient was converted to the second modality of treatment, i.e. conservative converted to pigtail insertion and patients with pigtail insertion converted to open drainage. In case of ultrasoundguided drainage procedures, patients were advised to continue the same antibiotics until the pus culture, and sensitivity results were available ${ }^{(3,4)}$

\section{Statistical Analysis}

Descriptive statistics were expressed as the mean and standard deviation. Chi square test/Fischer test was employed to compare the improvement in parameters between the groups.

\section{Observation}

The study was conducted on 40 patients divided under 2 groups(Conservative management and Ultrasound-guided pigtail drainage). Interventions were done under aseptic conditions. Statistical differences were found in the following variables.

Table 1- Age distribution among the patients

\begin{tabular}{|l|c|c|c|}
\hline Age in years & Group -I & Group -II & Total \\
\hline$<20$ & $0(0.0)$ & $3(15.0)$ & $3(7.5)$ \\
\hline $20-30$ & $6(30.0)$ & $2(10.0)$ & $8(20.0)$ \\
\hline $31-40$ & $8(40.0)$ & $7(35.0)$ & $15(37.5)$ \\
\hline $41-50$ & $2(10.0)$ & $3(15.0)$ & $5(12.5)$ \\
\hline $51-60$ & $4(20.0)$ & $3(15.0)$ & $7(17.5)$ \\
\hline$>60$ & $0(0.0)$ & $2(10.0)$ & $2(5.0)$ \\
\hline TOTAL & 20 & 20 & 40 \\
\hline p=0.192
\end{tabular}

Range of Group-I is 22-56 years with mean of 37.6 years, and Group -II with mean of 39.8years. There was no statistical difference between the two mean groups $(p>0.05)$. Maximum number of cases were noted in the age group of 31-40 years.

Table 2 - Distribution according to the duration of symptoms

\begin{tabular}{|l|c|c|c|}
\hline $\begin{array}{l}\text { Duration of } \\
\text { symptoms }\end{array}$ & GROUP-I & GROUP-II & TOTAL \\
\hline$<5$ days & $8(40.0)$ & $2(10.0)$ & $10(25)$ \\
\hline 6 - 10 days & $10(50.0)$ & $4(20.0)$ & $14(35.0)$ \\
\hline $11-15$ days & $1(5.0)$ & $4(20.0)$ & $5(12.5)$ \\
\hline $16-20$ days & $1(5.0)$ & $2(10.0)$ & $3(7.5)$ \\
\hline$>21$ days & $0(0.0)$ & $8(40.0)$ & $8(20.0)$ \\
\hline TOTAL & 20 & 20 & 40 \\
\hline
\end{tabular}
$\mathrm{p}=0.003$

The mean duration of symptoms at presentation in group-I $(n=20)$ was 13.45 days and in group II $(n=20)$ was 17.20 days. This difference between the two groups was found to be statistically significant.

Table 3 Distribution according to amoebic serology

\begin{tabular}{|l|c|c|c|}
\hline $\begin{array}{l}\text { AMOEBIC } \\
\text { SEROLOGY }\end{array}$ & GROUP-I & GROUP-II & TOTAL \\
\hline POSITIVE & 18 & 17 & 35 \\
\hline NEGATIVE & $\mathbf{0 2}$ & 03 & 05 \\
\hline TOTAL & 20 & 20 & 40 \\
\hline
\end{tabular}

Amoebic serology was positive in 18patients in Group -I and 17 patients in Group -II

\section{Ultrasonographic Finding}

All ultrasound examination of the abdomen was routinely performed at admission to assess the site, number, size and any associated complication of the ALA.

Table 4: Distribution according to number of abscesses

\begin{tabular}{|l|c|c|}
\hline & FREQUENCY & PER CENT \\
\hline MULTIPLE & 30 & $75 \%$ \\
\hline SINGLE & 10 & $25 \%$ \\
\hline TOTAL & 40 & $100 \%$ \\
\hline
\end{tabular}

Table 5: Distribution according to the side of abscess

\begin{tabular}{|l|c|c|}
\hline MULTIPLE ABSCESS & FREQUENCY & PERCENT \\
\hline LEFT & 05 & $16 \%$ \\
\hline RIGHT & 25 & $83 \%$ \\
\hline TOTAL & 30 & $100 \%$ \\
\hline
\end{tabular}

Thus, it was noticed that in 30 patients, multiple abscesses were noted of which 25 were in the right lobe, and 5 were in the left lobe.

Table 6: Distribution according to Size of Amoebic liver abscess at the time of admission

\begin{tabular}{|l|c|c|c|}
\hline DIAMETER & GROUP-I & GROUP-II & TOTAL \\
\hline 6CMS & 02 & 00 & 02 \\
\hline 7CMS & 02 & 01 & 03 \\
\hline 8CMS & 08 & 04 & 12 \\
\hline 9CMS & 07 & 08 & 15 \\
\hline 10CMS & 01 & 07 & 08 \\
\hline TOTAL & 20 & 20 & 40 \\
\hline
\end{tabular}

The mean maximum diameter was $8.45+\_0.71$ in Group-I and 8.75+-0.71 in Group-II 
Table 7: Distribution according to the change in the size of Amoebic liver abscess at $72 \mathrm{hrs}$ after admission.

\begin{tabular}{|l|c|c|c|}
\hline DIAMETER & GROUP-I & GROUP-II & TOTAL \\
\hline 6CMS & 07 & 09 & 16 \\
\hline 7CMS & 06 & 06 & 12 \\
\hline 8CMS & 04 & 03 & 07 \\
\hline 9CMS & 02 & 02 & 04 \\
\hline 10CMS & 01 & 00 & 1 \\
\hline TOTAL & 20 & 20 & 40 \\
\hline
\end{tabular}
$\mathrm{p}=0.8459$

Among the cases, the mean maximum diameter was $7.75 \pm 0.71$ with a range of 6.0 to $9.0 \mathrm{~cm}$ and among the controls mean maximum diameter was $8.00 \pm 0.72$ with a range of 6.0 to $10.0 \mathrm{~cm}$.

The difference between the two means was 0.725 , and this change in diameter from admission to 72 hours was statistically significant.

Table 8: Distribution of Total Leukocyte Count (TLC) at admission

\begin{tabular}{|l|c|c|c|}
\hline $\begin{array}{l}\text { TOTAL } \\
\text { LEUCOCYTE } \\
\text { COUNT }\end{array}$ & GROUP-I & GROUP-II & TOTAL \\
\hline$<10,000$ & 01 & 03 & 04 \\
\hline $10,000-15,000$ & 07 & 08 & 15 \\
\hline $15,000-20,000$ & 09 & 06 & 15 \\
\hline$>20,000$ & $03(15 \%)$ & 03 & 06 \\
\hline TOTAL & 20 & 20 & 40 \\
\hline
\end{tabular}

$\mathrm{p}=0.6436$

The mean value of TLC in study Group I patients at admission was $13700 \pm 5937 \mathrm{cell} / \mathrm{mm}^{3}$ (range 6800 to 32300 cells $/ \mathrm{mm}^{3}$ ), while in study Group II patients the mean value was $16812 \pm 6832$ cell $/ \mathrm{mm}^{3}$ (range 8200 to 32300 cells $/ \mathrm{mm}^{3}$ ).

Table 9: Distribution of Total Leukocyte Count (TLC) at $72 \mathrm{hrs}$

\begin{tabular}{|l|c|c|c|}
\hline $\begin{array}{l}\text { TOTAL } \\
\text { LEUCOCYTE } \\
\text { COUNT }\end{array}$ & GROUP - I & GROUP-II & TOTAL \\
\hline$<5,000$ & 02 & 03 & 05 \\
\hline $5,000-10,000$ & 05 & 06 & 11 \\
\hline $10,000-15,000$ & 09 & 08 & 17 \\
\hline $15,000-20,000$ & 03 & 03 & 06 \\
\hline$>20,000$ & 01 & 00 & 01 \\
\hline TOTAL & 20 & 20 & 40 \\
\hline$p=0.8528$ & & & \\
\hline
\end{tabular}

\section{$\mathrm{p}=0.8528$}

The mean value of TLC at $72 \mathrm{hrs}$ was $8645 \pm$ 3096 cell $/ \mathrm{mm}^{3}$ (95\% CI: 4315- 8276) study patients. The change in TLC from admission to 72 hours was statistically significant.
Table 10: Visual Analog Scale (VAS) of pain at admission

\begin{tabular}{|l|c|c|c|}
\hline VAS & GROUP-I & GROUP-II & TOTAL \\
\hline $0-3$ & 02 & 03 & 05 \\
\hline $4-6$ & 06 & 05 & 11 \\
\hline $7-8$ & 07 & 08 & 15 \\
\hline $9-10$ & 05 & 04 & 09 \\
\hline TOTAL & 20 & 20 & 40 \\
\hline
\end{tabular}

$\mathrm{P}=0.9254$

The mean VAS of pain at admission in patients was $6.02 \pm 2.75$.

Table 11: Visual Analog Score (VAS) of pain in the study population at $72 \mathrm{hrs}$

\begin{tabular}{|l|c|c|c|}
\hline VAS & GROUP-I & GROUP - II & TOTAL \\
\hline $0-3$ & 08 & 09 & 17 \\
\hline $4-6$ & 07 & 06 & 13 \\
\hline $7-8$ & 03 & 03 & 06 \\
\hline $9-10$ & 02 & 02 & 04 \\
\hline TOTAL & 20 & 20 & 40 \\
\hline
\end{tabular}

$\mathrm{p}=0.9866$

The mean VAS of pain at 72 hours in study patients was $1.68 \pm 2.786$.

The difference between the means of VAS at admission and at 72 hours was 4.35 (95\% CI: 3.39- 5.31), and this difference was found to be statistically significant .

Table 12: Distribution of duration of hospital stay

\begin{tabular}{|l|c|c|c|}
\hline $\begin{array}{l}\text { DURATION } \\
\text { OF STAY }\end{array}$ & GROUP-I & GROUP-II & TOTAL \\
\hline$<10$ DATYS & 17 & 05 & 22 \\
\hline 11-20 DAYS & 03 & 07 & 10 \\
\hline $21-30$ DAYS & 00 & 06 & 06 \\
\hline$>30$ DAYS & 00 & 02 & 02 \\
\hline TOTAL & 20 & 20 & 40 \\
\hline
\end{tabular}

Mean duration of hospital stay in Group I was 6.95 days and in Group II was 17.20 days. There is a statistically significant difference between Group I and Group II.

Table 13: Various types of Air cavitogram

\begin{tabular}{|l|c|c|}
\hline & FREQUENCY & PER CENT \\
\hline SUGGESTIVE OF NO FLUID LEVEL & 09 & 22.5 \\
\hline SUGGESTIVE OF MINIMAL FLUID & 04 & 10 \\
\hline $\begin{array}{l}\text { SUGGESTIVE OF SMALL CAVITY } \\
\text { WITH AIR ONLY }\end{array}$ & 03 & 7.5 \\
\hline $\begin{array}{l}\text { SUGGESTIVE OF SUBSTANTIAL } \\
\text { FLUID INSIDE THE CAVITY }\end{array}$ & 02 & 5 \\
\hline $\begin{array}{l}\text { SUGGESTIVE OF SUBSTANTIAL } \\
\text { FLUID LEVEL }\end{array}$ & 02 & 5 \\
\hline TOTAL & 20 & 100 \\
\hline
\end{tabular}


In Group I, the 20 patients (3 patients were converted to Study Group II vide supra), were discharged once they became asymptomatic and the abscess cavity was found reduced in size on ultrasound. In Group II the abscess was considered resolved on the basis of ultrasound findings at the time of pigtail catheter removal when the size of the abscess was found to be markedly decreased, and the air cavitogram showed nil/minimal residual fluid.

\section{Outcome of Management in the Study Group Conversion to Alternative Treatment}

Due to persistence of fever, increase in the pain score at $72 \mathrm{hr}$, failure to reduce the total leucocyte count and increase in the size of the abscess treatment modality was changed for three patients from conservative management to pigtail catheter drainage insertion. However, initial pigtail inserted patients needed no change in the treatment modality, and showed improvement.

\section{Follow Up}

Group I patients were followed up by Ultrasound examination at regular intervals to note the size of the abscess, whereas in Group II patients with catheter when stopped draining air cavitogram was done and also ultrasound examination to note the quantity of the residual fluid in the cavity

\section{Complications of Pigtail Drainage}

i. Technical complications $(n=4)$-wrong placement $(n=3)$, displacement of catheter $(\mathrm{n}=1)$

ii. The leak of contrast into the peritoneal cavity during cavitogram $(\mathrm{n}=1)$.

iii. Bile leak $(n=6)$

Table 14: Total serum bilirubin \&Serum Alkaline Phosphatase (ALP)

\begin{tabular}{|l|c|c|c|c|}
\hline & $\begin{array}{c}\text { GROUP- } \\
\text { I }\end{array}$ & $\begin{array}{c}\text { GROUP- } \\
\text { II }\end{array}$ & MEAN & RANGE \\
\hline $\begin{array}{l}\text { S. BILIRUBIN } \\
\text { (mg/dl) }\end{array}$ & 0.55 & 0.94 & 0.91 & $0.4-1.4$ \\
\hline $\begin{array}{l}\text { S.ALKALINE } \\
\text { PHOSPHATE(KA) }\end{array}$ & 23.3 & 21.4 & 22.3 & $4-46 \mathrm{KA}$ \\
\hline
\end{tabular}

\section{Discussion}

In the present study among 40 patients, 20 each were there in Group -I \&II for comparing the two modalities of treatment of uncomplicated amoebic liver abscess I .e. conservative management versus ultrasound-guided pigtail drainage of amoebic liver abscess measuring between 6.0 and $10.0 \mathrm{~cm}$ in the maximum diameter.

In our study, the mean age of the patients was 37.19 years (range 36-50years) with the maximum number $(n=16)$ of patients were in the age group of $36-50$ years $(40 \%)$. In the present study, the mean duration of symptoms at presentation in the Group I was 13.45 days (range 1-60 days). While the mean duration of symptoms at presentation in Group II was 17.20 days. Studies by Ochsner et al. reported the duration of symptoms as 1 day with an average of 10days to 2 weeks in acute Group whereas, in chronic Group, it was 3 years with an average of 3-6 months ${ }^{(5)}$. Salles et al. reported in his study that the duration of symptoms to varying from 4 days to 12 weeks but most of the patients presented within two weeks of the onset of symptoms. ${ }^{(6)}$ The average duration of symptoms has also been reported to be $2 \frac{1 / 2}{2}$ months according to a study by Shabot et al. ${ }^{(7)}$ The amoebic serology was positive in $18 / 20$ cases of Group (90\%). It was positive in $85 \%$ of cases in Group II. Studies by Gandhi et al. and Lodhi et al. had reported $79.1 \%$ positive amoebic serology in cases of amoebic liver abscess patients. ${ }^{(9,10)}$ A study was done by Mathur et al., 79 out of 82 patients $(96.3 \%)$ of amoebic liver abscess were reported to be positive for amoebic serology. In endemic areas, serological tests are helpful in evaluating the risk of invasive amoebas in asymptomatic cyst passer as they also develop antibodies. ${ }^{(1)}$ The mean value of total serum bilirubin in Group -I was $0.55 \mathrm{mg} / \mathrm{dl}$, Group II was $0.94 \mathrm{mg} / \mathrm{dl}$. The mean value of $1.9 \mathrm{mg} / \mathrm{dl}$ for total bilirubin had been reported in studies done by Lodhi et al. and Khanna et al. ${ }^{(10,12)}$ Another study by Sharma et al. had reported the Bilirubin level of $>3.5 \mathrm{mg} / \mathrm{dl}$ was associated with a worse prognosis. ${ }^{(13)}$ Serum Alkaline Phosphatase has the 
mean value of $23.30 \mathrm{KA}$ in group-I, whereas, in Group II, it is $21.4 \mathrm{KA}$. Earlier reports by Khanna et al. showed raised ALP in $76 \%$ of cases of Amoebic liver abscess. ${ }^{(12)}$ Thus, ALP is the most reliable and consistent biochemical indicator of Amoebic liver abscess. Mean TLC value at admission in Group. I was 13,700 cells $/ \mathrm{mm}^{3}$ (range $6800-32,300$ cells $/ \mathrm{mm}^{3}$ )and in Group II was 16812 cells $/ \mathrm{mm}^{3}$ (range 8200 to 32,300 cells $/ \mathrm{mm}^{3}$ ). A TLC of above 20000 cells $/ \mathrm{mm}^{3}$ indicates secondary infection of amebic liver abscess or a pyogenic abscess was given by Lamont $^{(14)}$ In the present study, right lobe is involved in 25 cases ( $83 \%$ ) and left lobe in 5 cases $(16 \%)$ of 30 cases of multiple abscesses. In the study of Gandhi et al., amoebic liver abscess $73 \%$ of cases involve right lobe, $17 \%$ involve left lobe and both lobe involvement in $10 \%$ cases. ${ }^{9}$ Solitary ALA had been reported in $77 \%$ cases and multiple in $23 \%$ cases. $^{(9)}$ Thus, the reported involvement of different lobes in our study correlates well with earlier studies. The mean abscess diameter was $7.4 \mathrm{~cm} .{ }^{(17)}$. Other studies by Gandhi et al. had reported the mean largest abscess diameter as $7.0 \mathrm{~cm} .{ }^{(9)}$ Clinical, biochemical and ultrasound parameters were observed at the time of admission and 72 hours later to check for the progress of particular modality of treatment. Medical management for uncomplicated ALA is indicated if the size of the abscess is $5 \mathrm{~cm}$ or less ${ }^{(17,18,19)}$ while therapeutic aspiration is indicated if the volume of abscess exceeds $200 \mathrm{ml1} .^{(20)}$ The present study is comparing the efficacy of medical treatment versus pigtail insertion for amoebic liver abscess measuring 6.0 to $10.0 \mathrm{~cm}$, which in literature have been treated subjectively without clearly identifying the treatment parameters. In our study, there was not much difference in the size of amoebic liver abscess in the two groups under study. Further, our study showed that the abscesses of size between 6.0 to $10.0 \mathrm{~cm}$ could be taken for pigtail catheter drainage initially at presentation as the time of resolution was more rapid in Group II as compared to Group I. Mean duration of hospital stay in Group I was 6.95 days and in Group II was 17.2 days. Thus our study clearly proves that the resolution of uncomplicated solitary right lobe liver abscess measuring between 6.0 to $10.0 \mathrm{~cm}$ was faster and earlier if the ALA was drained with a pigtail catheter than in patients who were managed conservatively. The study clearly indicates that uncomplicated abscesses measuring 6.0 to 10.0 $\mathrm{cm}$ are better treated with pigtail insertion under Sonographic control. Other indications for pigtail insertion are abscesses measuring more than 10.0 $\mathrm{cm}$ and those ALA associated with complications. Abscesses less than $6.0 \mathrm{~cm}$ can be managed with medical treatment alone.

\section{Conclusion}

Our study clearly proves that the resolution of uncomplicated solitary right lobe liver abscess measuring between 6.0 to $10.0 \mathrm{~cm}$ was faster and easier if the Amoebic liver abscess was drained with a pigtail catheter than in patients who were managed conservatively. Abscess less than $6 \mathrm{~cm}$ can be managed with medical treatment alone.

\section{References}

1. Seeto RK, Rockey DC. Pyogenic liver abscess. Changes in etiology, management, and outcome. Medicine (Baltimore). 1996;75(2):99-113.

2. Krige JE, Beckingham IJ. ABC of diseases of liver, pancreas and biliary system: liver abscesses and hydatid disease. BMJ 2001;322(7285):53

3. Farges O, Leese T, Bismuth H. Pyogenic liver abscess: an improvement in prognosis Br J Surg. 1988;75:862-5

4. Barbour G. L. and Juniper K. A clinical comparison of amebic and pyogenic abscess of the liver in sixty- six patients. Am J Surg. 1972;53:323-34

5. Ochsner A, DeBakey M. Amebic hepatitis and abscess (an analysis of 181 cases with review of literature). Surgery 1943; 13: 612-49. Petri Jr WA, Singh U. State of the art clinical article- Diagnosis and 
Management of Amoebiasis. Clin Infect Dis 1999; 29: 1117-25.

6. Salles MJ, Moraes AL, salles CM. Hepatic amebiasis. Braz $\mathbf{J}$ Infect Dis 2003;7:1-2

7. Shabot MJ, Patterson M. Amebic liver abscess: 1966-1976. Dig Dis 1978;23:11018.

8. Petri Jr WA, Singh U. State of the art clinic article- Diagnosis and Management of Amoebiasis. Clin Infect Dis 1999; 29:1117-25.

9. Gandhi BM, Irshad M, Acharya SK, Tandon BN. Amebic liver abscess and Circulating immune complexes of Entamoeba Histolytica portiens . Am J Trop Med hyg 1988; 39:440-44.

10. Lodhi S, Sarwari AR, Muzamil M, Salam A, Smego A, Smego RA. Features distinguishing amoebic from pyogenic liver abscesses: a review of 577 adult cases. Trop Med Int Health 2004;9: 71823.

11. Mathur S, Gehlot SR, Mohta A, Bhargava N. Clinical profile of amoebic liver abscess. J Ind Acad Clin Med 2002; 3: 367-73.

12. Khanna S, Chaudhary O, Kumar A, Vij JC Experience with aspiration in amoebic liver abscess. Report from an endemic area. Eur J Clin Microbiol Infect Dis 2005;24: 428-30

13. Sharma MP, Dasarathy S, Verma N, saksena S, Shukla KD. ProGnostic markers in Amebic liver abscess: a prospective study Am J Gastroenterol 1996; 91: 2584- 88.

14. Lamont NM, Pooler NR. Hepatic amoebiasis.A study of 250 cases. Quart J Med New Ser 1958; 27: 389-441.
15. Ramachandran S, Goontiallke HD, Induruwa PAC. Syndromes in amoebic liver Abscess. Br J Surg 1976; 63:220-25

16. Blessmann J, Binh Duy Hung Manh 0, Tannich E, Burchard G. Treatment of Amoebic liver abscess with metronidazole alone or in combination with ultrasound Guided needle aspiration: a comparative, prospective, and randomized study.Trop Med Int Heaith 2003; 8: 1030-34.

17. Allan Van JR, Katz OM, Johnson BM, Laine AL, Liu Y, Ralls WP. Uncomplicated amebic liver abscess: a prospective evaluation of percutaneous therapeutic aspiration. Radiology 1992; 183: 827-30. 46.

18. Kapadia S, Duttaroy D, Ghodgaonkar p, Maru S. Percutaneous catheter drainage of liver abscesses.Indian J Surgery 2002; 64: 516-19.

19. Zafar A, Ahmed S. Amoebic liver abscess; a comparative study of needle aspiration versus conservative management. J Ayub Med Coli Abbottabad 2002;14:10-12

20. Tsai Ho S. Experiences in the therapy of amebic liver abscess on Taiwan. Am J Trap Med Hyg 1973; 22: 24-9. 